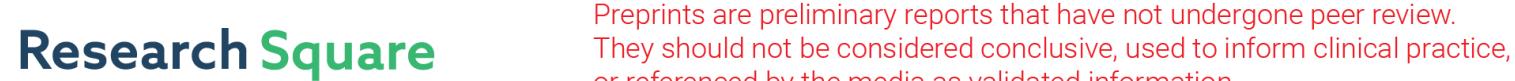 or referenced by the media as validated information. \\ The Prevalence and Associated Factors of Depression Among Residents in Training
}

\section{Nuntaporn Karawekpanyawong}

Chiang Mai University

Kamolchanok Chimnuan

Chiang Mai University

\section{Saranat Orrapin}

Chiang Mai University

\section{Suttipong Kawilapat}

Chiang Mai University

\section{Punjaree Wiriyacosol ( $\sim$ Punjaree.w@cmu.ac.th )}

Chiang Mai University

\section{Research Article}

Keywords: depression, physician in training, loneliness, emotional intelligence, burnout

Posted Date: January 17th, 2022

DOI: https://doi.org/10.21203/rs.3.rs-1234632/v1

License: (1) This work is licensed under a Creative Commons Attribution 4.0 International License. Read Full License 


\section{Abstract}

Background: Residency training causes high stress and leads to depression.

Aims: This study aims to investigate the prevalence and factors associated with depression in residents.

Methods: This cross-sectional, single-site study was conducted on residents from March to July 2020. We used the nine-item Patient Health Questionnaire (PHQ-9) to determine depression. We use binary logistic regression to evaluate associated factors: Ioneliness, burnout, sleep quality, Emotional quotients (EQ), and perceived social support (PSS).

Results: About one-fifth of residents had depression (47 of 201), $6.97 \%$ of students had suicidality. Factors showing a positive correlation with depression included: loneliness (aOR: 1.27; 95\%Cl: 1.15-1.40); burnout syndrome in depersonalization (aOR: 1.18; 95\%Cl: 1.10-1.25), and reduced personal accomplishment (aOR: 1.10; 95\% Cl: 1.05-1.14). Factors showing a negative correlation with depression included: perceived social support from significant others (aOR: $0.91 ; 95 \% \mathrm{Cl}: 0.85-0.98$ ); three subscales of EQ included motivation (aOR: 0.82; 95\%Cl: 0.68-0.99); life satisfaction (aOR: 0.83; 95\%Cl: 0.70-0.97); level of peace (aOR: $0.76 ; 95 \% \mathrm{Cl}: 0.66-0.87)$.

Conclusions: Depression in residents was $23.40 \%$. Loneliness, low social support, and burnout (depersonalization, reduced personal accomplishment) were associated with depression. EQ (motivation, life satisfaction, and peace) might reduce depression.

\section{Introduction}

Depression is characterized by persistent sadness or anhedonia, feelings of worthlessness, and physical symptoms (lack of energy, loss of appetite, and insomnia). The World Health Organization (WHO) revealed that 322 million people, estimated to be $4.40 \%$ globally, have depression, and depression increased $18.40 \%$ over 10 years [1]. Previous studies found a higher prevalence of depression among physicians than the general population, especially among physicians in training [2]. The reported prevalence of depression among medical residents was $19.00 \%-43.25 \%$ globally and in Thailand [2-7].

Depression causes distress, dysfunction, self-harm, and suicide (often homicide) [8]. Disability from depression among physicians can affect their daily living, studying, and caring for patients [2]. Understanding the impact and factors associated with depression is essential to design preventive interventions for residents.

Substantial research was conducted to understand determinants of depression among residents and found potential risks included: being female, having depression in the past, working more than 80 hours per week, and feeling burned out $[6,7,9]$. However, the limited studies focused on their strength in preventing depression, such as EQ or social support [10]. Therefore, this study aimed to determine the 
prevalence and factors associated with depression (potential risk and strength) among residents. We expected that our result could be used in strategic planning for preventing depression.

\section{Materials And Methods \\ Study design}

This cross-sectional study was conducted among residents at the Faculty of Medicine, Chiang Mai University, from March to July 2020. This study was approved by the Research Ethics Committee, Faculty of Medicine, Chiang Mai University (reference number 041/6957)

\section{Participants}

This study included all residents at the Faculty of Medicine, Chiang Mai University, in the 2019 academic year. The inclusion criteria were fluency in the Thai language. Exclusion criteria were unwilling participants or incomplete questionnaires. Participants received an invitation, consent form, and questionnaires via an online platform, and they completed questionnaires privately without compulsion and any compensation. All anonymous responses were confidential. Incomplete questionnaires were not recorded in our database.

Two types of physicians are enrolled in our postgraduate programs. The first is the physicians who have become general practitioners before the training called "Residents". The second type is "Interns" which are physicians who enrolled in the training programs immediately following completion of medical school. The first year of their training is working as a general practitioner. Following the first intern year, the interns pursue their specialty training.

\section{Assessment}

The following sociodemographic characteristics data, five strongly related factors of depression, and depression were collected.

\section{Sociodemographic characteristics}

Sociodemographic characteristics included: age, sex, marital status, hometown, institutions from which they received a medical degree, year of training, years of general practice before training, income (Baht per month), overtime working hours per week, medical underlying disease, psychiatric history, family psychiatric history, and alcohol drinking.

\section{Burnout syndrome}

The Thai version of the Maslach Burnout Inventory, a 22-item self-report, was used to evaluate burnout which includes emotional exhaustion (EE; Cronbach's alpha $=0.92$ ), depersonalization (DP; Cronbach's alpha $=0.66)$, and reduced personal accomplishment (PA; Cronbach's alpha $=0.65)$. Each subscale has a seven-point Likert scale from 0 (never) to 7 (every day) in negative questions and 7 (every day) to 0 
(never) in positive questions. The higher summary scores of EE and DP but lower summary scores of PA refer to higher burnout [11].

\section{Loneliness}

The Thai version of the 6-Item Revised UCLA Loneliness Scale (RULS-6), a short version of the UCLA Loneliness Scale, was modified and tested by Nahathai Wongpakaran, et al. Cronbach's alpha of the RULS-6 was 0.83. This questionnaire measures loneliness such as “How often do you feel alone?”. Each item used a four-point Likert scale, that is, 1 (often), 2 (sometimes), 3 (rarely), and 4 (never). A higher score indicates a higher loneliness level [12].

\section{Perceived social support}

The revised Thai version of the Multidimensional Scale of Perceived Social Support (r-T-MSPSS) was used to measure individuals' perceived social support from three sources: Significant Others (SO), Family (FA), and Friends (FR). These 12-items self-report questionnaire responses are a seven-point Likert scale ranging from 1 (very strongly disagree) to 7 (very strongly agree). The higher scores refer to higher social support that individuals perceive in each source [13].

\section{Emotional quotients (EQ)}

The Department of Mental Health, Ministry of Public Health developed an EQ measurement for Thai people aged 18-60 years old [14]. This self-report measures nine subscales of EQ: emotional self-control, empathy, responsibility, self-motivation, problem-solving, interpersonal relationships, self-regard, life satisfaction, and peace. The rating scale is a four-point Likert scale with scores ranging from 1 (not true) to 4 (very true) in positive questions and 4 (not true) to 1 (very true) in negative questions. Overall's Cronbach's alpha is 0.85 [15].

\section{Sleep quality}

The Thai Version of the Pittsburgh Sleep Quality Index; T-PSQI is a 19-item self-report questionnaire that evaluated sleep quality in the past month, consisting of seven component scores. Each component point ranges from 0 (no difficulty) to 3 (severe difficulty), with a total PSQI score $>5$ defined as poor sleep quality (Cronbach's alpha 0.84) [16].

\section{Depression}

Depression was determined by using the Thai version of the nine-question Patient Health Questionnaire Scale (PHQ-9). This self-report questionnaire refers to depressive symptoms experienced in the past two weeks ("Feeling down, depressed, or hopeless"). Scores for each item range from 0 (not at all) to 3 (nearly every day). The recommended cut-off score for depression is 9 . The severities of depression are classified as mild (5-9), moderate (10-14), moderately severe (15-19), and severe (20-27). The Thai version of PHQ-9 had good internal consistency (Cronbach's alpha $=0.79$ ) [17]

\section{Study size estimation}


The calculated sample size was 260 using the formula " $N=Z^{2} P Q / E^{2 n}$ regarding our primary objective.

- $\mathrm{N}$ determines sample size from the calculation.

- $Z$ determines the value from the table of probabilities of the standard normal distribution for the desired confidence level (e.g., $Z=1.96$ for $95 \%$ confidence).

- P determines the prevalence from the previous study, which was $21.52 \%$ [6].

- $\mathrm{Q}$ determines 1-P = 0.78. E determines a standard deviation of 0.50 .

From a previous study, the response rate was relatively low (38.50\%). Thus, we included all residents in training at Chiang Mai University in 2019 ( $N=598)$ to participate in the study without sampling.

\section{Statistical analysis}

Categorical data was calculated to percentage and compared with Fisher's exact test. For continuous data with normal distribution, we used Mean ( \pm standard Deviation; SD) and independent t-test. We used Median (Interquartile range; IQR) and Mann Whitney u test for continuous data with no normal distribution. Prevalence and severity of depression in residents were calculated to percentage. Association between factors and depression was analyzed using multivariable logistic analysis with univariable analysis preselection $(p<0.200)$. We divided factors into three models and analyzed them separately as follows.

- Model 1 included having underlying medical disease, category of training, a poor sleeper, and burnout (EE, DP, PA)

- Model 2 included loneliness and perceived social support (SO, FA, FR)

- Model 3 included nine subscales of EQ (emotional self-control, empathy, responsibility, selfmotivation, problem-solving, interpersonal relationships, self-regard, life satisfaction, and peace)

The effect sizes of association were presented as odds ratios (OR) with $95 \%$ confidence intervals (Cl). The statistical significance was 0.050 (two-sided).

\section{Results}

Two hundred and one of 598 (33.6\%) completed the questionnaire. The mean age was $28.18 \pm 0.15$ years old. Most participants were female (65.70\%). The majority were unmarried $(89.10 \%)$. Almost half of the participants studied in their hometown and $75.10 \%$ studied in the institution of their M.D. graduation. The plurality of the study participants was in their first-(33.30\%) and second-year (30.30\%). The participants who had medical underlying conditions were $12.40 \%$, had psychiatric history were $3.50 \%$. More than a half drank alcohol less than one time per month (84.60\%), see Table 1. 
Table 1

Sociodemographic characteristics of the participants

\begin{tabular}{|c|c|c|c|c|c|}
\hline \multicolumn{2}{|c|}{$\begin{array}{l}\text { Sociodemographic Data, } \\
\text { n (\%)/Mean } \pm \text { SD/Median } \\
\text { (IQR) }\end{array}$} & $\begin{array}{l}\text { All } \\
(n=201)\end{array}$ & $\begin{array}{l}\text { Depression } \\
(n=41)\end{array}$ & $\begin{array}{l}\text { Non-depression } \\
(n=154)\end{array}$ & $\begin{array}{l}\mathrm{p}- \\
\text { value }\end{array}$ \\
\hline \multicolumn{2}{|l|}{ Age } & $28(27-29)$ & $28(27-29)$ & $28(27-29)$ & 0.497 \\
\hline \multicolumn{2}{|l|}{ Female } & $132(65.70 \%)$ & $31(66.00 \%)$ & $101(65.60 \%)$ & 0.962 \\
\hline \multirow{4}{*}{$\begin{array}{l}\text { Marital } \\
\text { status }\end{array}$} & Single & $179(89.10 \%)$ & $42(89.40 \%)$ & $137(89.00 \%)$ & \multirow[t]{4}{*}{0.761} \\
\hline & Married & $12(6.00 \%)$ & $2(4.30 \%)$ & $10(6.50 \%)$ & \\
\hline & $\begin{array}{l}\text { (living } \\
\text { together) }\end{array}$ & & & & \\
\hline & $\begin{array}{l}\text { Married } \\
\text { (separated) }\end{array}$ & $10(5.00 \%)$ & $3(6.40 \%)$ & $7(4.50 \%)$ & \\
\hline \multicolumn{2}{|c|}{ Having a child (or children) } & $4(2.00 \%)$ & $2(4.30 \%)$ & $2(1.30 \%)$ & 0.204 \\
\hline \multicolumn{2}{|c|}{$\begin{array}{l}\text { Training place same as } \\
\text { hometown }\end{array}$} & $94(46.80 \%)$ & $20(42.60 \%)$ & $74(48.10 \%)$ & 0.508 \\
\hline \multicolumn{2}{|c|}{$\begin{array}{l}\text { Same training places as M.D. } \\
\text { graduation }\end{array}$} & $151(75.10 \%)$ & $35(74.50 \%)$ & $116(75.30 \%)$ & 0.905 \\
\hline \multirow[t]{2}{*}{ Category } & Intern & $90(44.80 \%)$ & $16(34.00 \%)$ & $74(48.10 \%)$ & \multirow[t]{2}{*}{0.091} \\
\hline & Resident & $111(55.20 \%)$ & $31(66.00 \%)$ & $80(51.90 \%)$ & \\
\hline \multicolumn{2}{|c|}{ Years of general practice } & $2(1-3)$ & $3(1-3)$ & $1.25(1-3)$ & 0.330 \\
\hline \multicolumn{2}{|c|}{ Income (Bath/month) } & $\begin{array}{l}35000(30000- \\
40000)\end{array}$ & $\begin{array}{l}35000(30000- \\
40000)\end{array}$ & $\begin{array}{l}35000(30000- \\
40000)\end{array}$ & 0.621 \\
\hline \multicolumn{2}{|c|}{ Over time (hours/week) } & $32(14-50)$ & $40(21-60)$ & $32(11-50)$ & 0.093 \\
\hline \multirow{5}{*}{$\begin{array}{l}\text { Year of } \\
\text { training }\end{array}$} & First & $67(33.30 \%)$ & $18(38.30 \%)$ & $49(31.80 \%)$ & \multirow[t]{5}{*}{0.290} \\
\hline & Second & $61(30.30 \%)$ & $16(34.00 \%)$ & $45(29.20 \%)$ & \\
\hline & Third & $45(22.40 \%)$ & $5(10.60 \%)$ & $40(26.00 \%)$ & \\
\hline & Fourth & $25(12.40 \%)$ & $7(14.90 \%)$ & $18(11.70 \%)$ & \\
\hline & Fifth & $3(1.50 \%)$ & $1(2.10 \%)$ & $2(1.30 \%)$ & \\
\hline \multicolumn{2}{|c|}{ Extra personal practice } & $32(15.90 \%)$ & $9(19.10 \%)$ & $23(14.90 \%)$ & 0.489 \\
\hline \multicolumn{6}{|c|}{ SD, standard deviation; IQR, interquartile ranges; M.D., medical doctor or Doctor of Medicine } \\
\hline \multicolumn{6}{|c|}{ Number in bold are for significant $p$-value at $<0.050$ (two-sided). } \\
\hline
\end{tabular}




\begin{tabular}{|c|c|c|c|c|c|}
\hline \multicolumn{2}{|c|}{$\begin{array}{l}\text { Sociodemographic Data, } \\
\text { n (\%)/Mean } \pm \text { SD/Median } \\
(\text { IQR) }\end{array}$} & $\begin{array}{l}\text { All } \\
(n=201)\end{array}$ & $\begin{array}{l}\text { Depression } \\
(n=41)\end{array}$ & $\begin{array}{l}\text { Non-depression } \\
(n=154)\end{array}$ & $\begin{array}{l}\mathrm{p} \text { - } \\
\text { value }\end{array}$ \\
\hline \multicolumn{2}{|c|}{ Underlying medical conditions } & $25(12.40 \%)$ & $2(4.30 \%)$ & $23(14.90 \%)$ & 0.052 \\
\hline \multicolumn{2}{|c|}{ Psychiatric history } & $7(3.50 \%)$ & $3(6.40 \%)$ & $4(2.60 \%)$ & 0.215 \\
\hline \multicolumn{2}{|c|}{ Family psychiatric history } & $4(2.00 \%)$ & $1(2.10 \%)$ & $3(1.90 \%)$ & 0.938 \\
\hline \multirow{4}{*}{$\begin{array}{l}\text { Alcohol } \\
\text { drinking }\end{array}$} & No & $93(46.30 \%)$ & $24(51.10 \%)$ & $69(44.80 \%)$ & \multirow[t]{4}{*}{0.761} \\
\hline & $\begin{array}{l}\leq 1 \\
\text { time/month }\end{array}$ & $77(38.30 \%)$ & $15(31.90 \%)$ & $62(40.30 \%)$ & \\
\hline & $\begin{array}{l}2-4 \\
\text { times/month }\end{array}$ & $28(13.90 \%)$ & $7(14.90 \%)$ & $21(13.60 \%)$ & \\
\hline & 2-3 times/week & $3(1.50 \%)$ & $1(2.10 \%)$ & $2(1.30 \%)$ & \\
\hline \multicolumn{6}{|c|}{ SD, standard deviation; IQR, interquartile ranges; M.D., medical doctor or Doctor of Medicine } \\
\hline \multicolumn{6}{|c|}{ Number in bold are for significant p-value at $<0.050$ (two-sided). } \\
\hline \multicolumn{6}{|c|}{ It should be next to the first paragraph of result. } \\
\hline
\end{tabular}

The prevalence of depression among residents was 47 of 201 (23.40\%). Seventy-five participants $(37.30 \%)$ had mild depression, which is lower than the cut-off level $(\geq 9)$. Moderate depression was $11.90 \%$, moderately severe depression was $2.50 \%$, and severe depression was $1.50 \%$. Suicidality in the depression group was overall $29.79 \%$ and increased according to the severity of depression shown in Figure 1. The proportion receiving treatment was relatively low (7 of $201: 3.48 \%$ ), even if they had suicidal ideation. In mild depression, 5 of 75 participants $(6.67 \%)$ had suicidal thoughts, but none of them had received treatment previously. Moderate depression with suicidal thoughts was $16.67 \%$, but $4.17 \%$ had received treatment. Surprisingly, $60 \%$ of participants with moderately severe depression had suicidal ideations, but none had received treatment. Only participants with severe depression and suicidal ideas were receiving treatment.

Regarding univariable analysis, all factors were significantly associated with depression, see Table 2 . However, multivariable logistic regression found loneliness and burnout syndromes (DP and PA) positively correlated with depression, perceived social support from significant others, and EQ (motivation, life satisfaction, and peace) were negatively correlated with depression; shown in Table 3. Having medical underlying disease negatively correlated with depression by aOR $0.21(p=0.055)$. 
Table 2

Factors associated with depression

\begin{tabular}{|c|c|c|c|c|c|}
\hline Factors, median (IOR) & $\begin{array}{l}\text { All } \\
(n=201)\end{array}$ & $\begin{array}{l}\text { Depression } \\
(n=41)\end{array}$ & $\begin{array}{l}\text { Non-depression } \\
(n=154)\end{array}$ & OR $(95 \% \mathrm{Cl})$ & $\begin{array}{l}\mathrm{p}- \\
\text { value }\end{array}$ \\
\hline \multicolumn{6}{|l|}{ Burnout } \\
\hline Emotional exhaustion & $\begin{array}{l}19(10- \\
28)\end{array}$ & $27(19-36)$ & $16(8-26)$ & $\begin{array}{l}1.07(1.04- \\
1.11)\end{array}$ & $\dot{0} 001$ \\
\hline Depersonalization & $6(3-13)$ & $13(9-19)$ & $6(3-10)$ & $\begin{array}{l}1.14(1.08- \\
1.21)\end{array}$ & $\hat{0} .001$ \\
\hline $\begin{array}{l}\text { Reduced personal } \\
\text { accomplishment }\end{array}$ & $\begin{array}{l}14(9- \\
23)\end{array}$ & $20(15-29)$ & $13(8-21)$ & $\begin{array}{l}1.06(1.03- \\
1.10)\end{array}$ & $\hat{0} .001$ \\
\hline Poor sleeper & $\begin{array}{l}119 \\
(59.2)\end{array}$ & $36(76.6)$ & $83(53.9)$ & $\begin{array}{l}2.80(1.33- \\
5.90)\end{array}$ & 0.007 \\
\hline Loneliness & $\begin{array}{l}12(9- \\
15)\end{array}$ & $15(13-18)$ & $11(8-14)$ & $\begin{array}{l}1.31(1.19- \\
1.45)\end{array}$ & $\begin{array}{l}<.001 \\
0.00\end{array}$ \\
\hline \multicolumn{6}{|l|}{ Perceived social support } \\
\hline Total & $\begin{array}{l}70(62- \\
75)\end{array}$ & $62(54-71)$ & $71.5(66-76)$ & $\begin{array}{l}0.92(0.89- \\
0.96)\end{array}$ & $\hat{0} .001$ \\
\hline Significant others & $\begin{array}{l}24(20- \\
25)\end{array}$ & $20(16-24)$ & $24(21-26)$ & $\begin{array}{l}0.87(0.82- \\
0.93)\end{array}$ & $\hat{0} .001$ \\
\hline Friends & $\begin{array}{l}24(21- \\
25)\end{array}$ & $21(18-24)$ & $24(22-26)$ & $\begin{array}{l}0.82(0.75- \\
0.90)\end{array}$ & $\hat{0} .001$ \\
\hline Family & $\begin{array}{l}24(22- \\
27)\end{array}$ & $22(19-24)$ & $24(22-27)$ & $\begin{array}{l}0.86(0.80- \\
0.93)\end{array}$ & $\hat{0} .001$ \\
\hline \multicolumn{6}{|l|}{ Emotional quotient } \\
\hline Self-control & $\begin{array}{l}19(17- \\
20)\end{array}$ & $17(14-19)$ & $19(18-21)$ & $\begin{array}{l}0.73(0.64- \\
0.84)\end{array}$ & $\hat{0} .001$ \\
\hline Empathy & $\begin{array}{l}18(16- \\
21)\end{array}$ & $17(15-19)$ & $19(17-21)$ & $\begin{array}{l}0.76(0.66- \\
0.88)\end{array}$ & $\hat{0} .001$ \\
\hline Responsibility & $\begin{array}{l}20(17- \\
21)\end{array}$ & $18(15-21)$ & $20(18-22)$ & $\begin{array}{l}0.82(0.73- \\
0.93)\end{array}$ & 0.001 \\
\hline Motivation & $\begin{array}{l}16(15- \\
17)\end{array}$ & $15(14-16)$ & $16(15-18)$ & $\begin{array}{l}0.75(0.64- \\
0.88)\end{array}$ & $\dot{L}_{0.001}$ \\
\hline
\end{tabular}

$\mathrm{IQR}$, interquartile ranges; $\mathrm{OR}$, odds ratio; $\mathrm{Cl}$, confidence interval

Number in bold are for significant $p$-value at $<0.050$ (two-sided).

It should be next to the third paragraph of results. 


\begin{tabular}{|c|c|c|c|c|c|}
\hline Factors, median (IOR) & $\begin{array}{l}\text { All } \\
(n=201)\end{array}$ & $\begin{array}{l}\text { Depression } \\
(n=41)\end{array}$ & $\begin{array}{l}\text { Non-depression } \\
(n=154)\end{array}$ & OR $(95 \% \mathrm{Cl})$ & $\begin{array}{l}\mathrm{p}- \\
\text { value }\end{array}$ \\
\hline Problem solving & $\begin{array}{l}17(15- \\
20)\end{array}$ & $15(14-18)$ & $18(15-20)$ & $\begin{array}{l}0.78(0.69- \\
0.89)\end{array}$ & $\hat{0} .001$ \\
\hline Relationship & $\begin{array}{l}17(16- \\
19)\end{array}$ & $16(15-17)$ & $17(16-20)$ & $\begin{array}{l}0.78(0.68- \\
0.90)\end{array}$ & 0.001 \\
\hline Self-esteem & $\begin{array}{l}11(10- \\
13)\end{array}$ & $11(9-11)$ & $12(11-13)$ & $\begin{array}{l}0.61(0.49- \\
0.76)\end{array}$ & $\begin{array}{l}< \\
0.001\end{array}$ \\
\hline Life satisfaction & $\begin{array}{l}19(17- \\
21)\end{array}$ & $17(15-19)$ & $20(17-21)$ & $\begin{array}{l}0.71(0.62- \\
0.82)\end{array}$ & $\begin{array}{l}< \\
0.001\end{array}$ \\
\hline Peace & $\begin{array}{l}19(16- \\
22)\end{array}$ & $15(15-18)$ & $21(17-23)$ & $\begin{array}{l}0.70(0.62- \\
0.79)\end{array}$ & $\dot{0} 001$ \\
\hline \multicolumn{6}{|c|}{ IQR, interquartile ranges; OR, odds ratio; $\mathrm{Cl}$, confidence interval } \\
\hline \multicolumn{6}{|c|}{ Number in bold are for significant $p$-value at $<0.050$ (two-sided). } \\
\hline It should be next to th & agrap & results. & & & \\
\hline
\end{tabular}


Table 3

Multivariable binary logistic regression

\begin{tabular}{|c|c|c|c|}
\hline Model & Variable (s) & aOR $(95 \% \mathrm{Cl})$ & p-value \\
\hline \multirow[t]{3}{*}{1} & Having medical underlying disease & $0.21(0.04-1.04)$ & 0.055 \\
\hline & Burnout (depersonalization) & $1.18(1.10-1.25)$ & $<0.001$ \\
\hline & Burnout (reduced personal accomplishment) & $1.10(1.05-1.14)$ & $<0.001$ \\
\hline \multirow[t]{2}{*}{2} & Loneliness & $1.27(1.15-1.40)$ & $<0.001$ \\
\hline & Perceived social support (significant others) & $0.91(0.85-0.98)$ & 0.009 \\
\hline \multirow[t]{3}{*}{3} & Emotional Quotient (self-motivation) & $0.82(0.68-0.99)$ & 0.041 \\
\hline & Emotional Quotient (life satisfaction) & $0.83(0.70-0.97)$ & 0.023 \\
\hline & Emotional Quotient (peace) & $0.76(0.66-0.87)$ & $<0.001$ \\
\hline \multicolumn{4}{|c|}{$\begin{array}{l}\text { Model } 1 \text { was adjusted with having medical underlying disease, category, burnout (emotional } \\
\text { exhaustion, depersonalization, reduced personal accomplishment), and poor sleeping. }\end{array}$} \\
\hline \multicolumn{4}{|c|}{$\begin{array}{l}\text { Model } 2 \text { was adjusted with loneliness and perceived social support (significant others, friends, and } \\
\text { family). }\end{array}$} \\
\hline \multicolumn{4}{|c|}{$\begin{array}{l}\text { Model } 3 \text { was adjusted with nine subscales of Emotional Quotient (emotional self-control, empathy, } \\
\text { responsibility, self-motivation, problem-solving, interpersonal relationships, self-regard, life } \\
\text { satisfaction, and peace) }\end{array}$} \\
\hline \multicolumn{4}{|c|}{ aOR, adjusted odds ratio; $\mathrm{Cl}$, confidence interval } \\
\hline \multicolumn{4}{|c|}{ Number in bold are for significant p-value at < 0.050 (two-sided). } \\
\hline \multicolumn{4}{|c|}{ It should be next to the third paragraph of results following Table 2 . } \\
\hline \multicolumn{4}{|c|}{ It should be next to the second paragraph of result. } \\
\hline
\end{tabular}

\section{Discussion}

\section{The prevalence of depression}

In this study, the prevalence of depression among residents was $23.40 \%$. Compared with previous studies, this prevalence of depression among residents was lower than around one-third worldwide [2], similar to one-fourth in Thailand [6, 7]. Suicidality in participants with depression was $29.79 \%$ (14 of 47), with a higher rate of suicidal ideation in more severe depression. Interestingly, even participants with mild depression had $6.67 \%$ suicidal ideation, However, no suicidal ideation was found in participants with no depressive symptoms (PHQ-9<5).

Treatment accessibility was problematic. Only $14.89 \%$ of the depression group received treatment. Not all participants who had suicidal ideations were in the treatment process. From this finding, institutions 
should have active screening with a lower cut-off level (PHQ-9 $\geq 5)$ and provide proper interventions in each group of depressive residents, even in mild-depressive groups. For example, according to limited resources, the interventions should be psychoeducation, counseling, or group psychotherapy in mild depressive residents. In more severe depressive groups, providing more accessible channels to see the psychiatrist or psychologist is necessary [18].

\section{Associative factors of depression}

Burnout syndrome and loneliness seem to be potential risks, whereas social support and EQ seem to be possible protective factors. Burnout syndrome, which is depersonalization, and a low level of personal accomplishment positively correlated with depression. Depersonalization is a negative view toward relations in a workplace causing isolation behaviors, insensitivity, and dehumanization [19, 20]. A sense of low personal accomplishment is incompetence, negative self-appraisal, and low achievement at work $[21,22]$. The interventions aimed at preventing burnout syndrome may be helpful for residents at risk for depression. Current evidence demonstrated that interventions reducing burnout included mindfulness, relaxation, self-development groups, and duty-hour limitations [23]. Organizations can reduce depression among residents by providing training programs on coping strategies, social support, social skills, selfefficacy, and leadership [20].

Loneliness, a perception of lacking intimate relationships or social relationships network, is a predictor of depression. The correlation between loneliness and depression might be explained in either biological or psychological ways. Biologically, feeling lonely causes increased cortisol levels that can affect the emotional brain (hippocampus), resulting in depression [24]. Psychologically, loneliness involves painful feelings of isolation, disconnectedness from others, and not belonging and is associated with low selfesteem, low social competence, and poorer quality social interactions [25]. Moreover, loneliness shares some common causes with depression, such as poor social skills, shyness, and a maladaptive attributional style [26]. Some studies found that programs to improve social skills, enhance social support, increase opportunities for social interaction, and address deficits in social cognition were strategies for loneliness reduction [27].

As discussed above, having social support might reduce loneliness and depression. Our study found that support from significant others (institutions, teachers, advisers, and co-workers) was more crucial among residents than support from family and friends. Institutions' roles in reducing depression might be increased non-violent communication among individuals in organizations [28].

Moreover, EQ (self-motivation, life satisfaction, and peace) might be a personal protective factor of depression. Self-motivation, the ability to pursue one's own goals, consisted of outcome controllability (the own abilities' estimation to control outcomes in an environment), outcome value (the expected reward or punishment for reaching an outcome), and effort costs (the effort requirements for reaching an outcome). Some theories explained decreasing self-motivation as symptoms of depression; some studies explained the association between self-motivation and depression through cognitive control ability. To have good self-motivation refers to a remarkable ability to control their cognition beyond emotion. People 
who have much self-motivation have a positive view of self, such as self-respect and self-esteem, preventing depression [29].

Life satisfaction is a subscale of the happiness component in EQ. Some evidence supports that emotionally intelligent persons perceive circumstances as less stressful which results in greater satisfaction with life [30,31]. Life satisfaction is a judgmental and cognitive process, which shows a subjective and worldwide expectation of a person's life quality. To increase life satisfaction for the residents, strengthening resilience at the individual level is important to make people more satisfied because they develop resources for living well [32]. Peace of mind is characterized by the affective states of internal peace and harmony. The people who had more peace of mind suffered less from psychological distress. Our study found that individuals who had a high level of peace had the possible internal protective factor for depression. The process of achieving peace of mind might involve balancing between the experiences of pleasure and pain. Practicing mindfulness based stress reduction and moodregulation processes that allow people to revert to their equilibrium state of peace of mind are useful strategies to coping with stressful events in daily life [33, 34].

The strength of this study is to define the protective predictor of depression among residents igniting the starting point of planning intervention to prevent depression. However, the study had limitations given the single site, cross-sectional nature, and small sample size. A further multiple-site longitudinal study with a larger sample size might benefit generalizability, causative explanation, and statistical power. In addition, the implication of our result should do with caution because of possible information bias from the nature of self-report questions.

\section{Conclusions}

More than twenty percent of depression among Northern Thai medical residents is higher than the general population, lower than medical residents worldwide, but like other Thai institutions. Intervention either decreasing loneliness, low social support, and burnout (depersonalization, reduced personal accomplishment) or improving EQ (motivation, life satisfaction, and peace) might reduce depression among residents.

\section{Declarations}

\section{Ethics approval and consent to participate}

This study was approved by the Research Ethics Committee, Faculty of Medicine, Chiang Mai University (reference number 041/6957) and we confirm that all methods were carried out in accordance with the guidelines and regulations.

Informed consent was obtained from all participants and all of the participants are over 16 .

\section{Consent for publication}

Page 12/16 
Not applicable

\section{Availability of data and materials}

The datasets generated and/or analysed during the current study are available in the figshare database repository, (DOIs: 10.6084/m9.figshare.16930657).

\section{Competing interests}

The authors declare that they have no competing interests

\section{Funding}

This study was supported by Chiang Mai University, Chiang Mai, Thailand, under grant [072/2563].

\section{Authors' contributions}

NK, KC, and PW conceptualized the study. NK, KC, and PW designed the method. NK, KC, PW, and SO collected information. NK, SK, and KC coded, analyzed data, interpreted data, and produced the first draft of the manuscript. All authors refined and approved the final version for submission.

\section{Acknowledgements}

Many thanks to the residents who participated in this study.

Notes on contributors

NK, KC, and PW conceptualized the study. NK, KC, and PW designed the method. NK, KC, PW, and SO collected information. NK, SK, and KC coded, analyzed data, interpreted data, and produced the first draft of the manuscript. All authors refined and approved the final version for submission.

Biographical note:

Nuntaporn Karawekpanyawong is an instructor of psychiatry at Chiang Mai University, teaching undergraduate and postgraduate students.

Kamolchanok Chimnuan is a psychiatric resident at Chiang Mai University.

Saranat Orrapin is an assistant professor of surgery at Chiang Mai University, has been the Associate Dean of the Faculty of Medicine, Chiang Mai University.

Suttipong Kawilapat is a statistician at the Department of Psychiatry, Faculty of Medicine, Chiang Mai University

Punjaree Wiriyacosol is an instructor of psychiatry at Chiang Mai University, teaching undergraduate and postgraduate students. 


\section{References}

1. World Health Organization: Depression and other common mental disorders: global health estimates. In.: World Health Organization; 2017.

2. Mata DA, Ramos MA, Bansal N, Khan R, Guille C, Di Angelantonio E, Sen S: Prevalence of depression and depressive symptoms among resident physicians: a systematic review and meta-analysis. JAMA 2015, 314(22):2373-2383.

3. Pasqualucci PL, Damaso LLM, Danila AH, Fatori D, Neto FL, Koch VHK: Prevalence and correlates of depression, anxiety, and stress in medical residents of a Brazilian academic health system. $B M C$ medical education 2019, 19(1):1-5.

4. Lin DT, Liebert CA, Esquivel MM, Tran J, Lau JN, Greco RS, Mueller CM, Salles A: Prevalence and predictors of depression among general surgery residents. Am J Surg 2017, 213(2):313-317.

5. Pereira-Lima K, Loureiro S: Burnout, anxiety, depression, and social skills in medical residents. Psychology, health \& medicine 2015, 20(3):353-362.

6. Kaewpornsawan $\mathrm{T}$, Chaiudomsom $\mathrm{C}$ : The prevalence and associated factors of depression among residents in training at Faculty of Medicine, Siriraj Hospital. J Psychiatr Assoc Thailand 2014, 59:4150.

7. Thamrongvisava S, Pitanupong J: Prevalence and Associated Factors of Burnout Syndrome among Residents in Training at Faculty of Medicine, Songklanagarind Hospital. Journal of the Psychiatric Association of Thailand 2018, 63(4):309-320.

8. Goebert D, Thompson D, Takeshita J, Beach C, Bryson P, Ephgrave K, Kent A, Kunkel M, Schechter J, Tate J: Depressive symptoms in medical students and residents: a multischool study. Academic medicine 2009, 84(2):236-241.

9. Bailey E, Robinson J, McGorry P: Depression and suicide among medical practitioners in Australia. Internal medicine journal 2018, 48(3):254-258.

10. Joules N, Williams DM, Thompson AW: Depression in resident physicians: a systematic review. Open Journal of Depression 2014, 2014.

11. Burnout among the staff nurses in Ramathibodi Hospital. In.: Nakhon Pathom, Thailand: Mahidol University library and Information Center ...

12. Wongpakaran N, Wongpakaran T, Pinyopornpanish M, Simcharoen S, Suradom C, Varnado P, Kuntawong P: Development and validation of a 6-item Revised UCLA Loneliness Scale (RULS-6) using Rasch analysis. British journal of health psychology 2020, 25(2):233-256.

13. Wongpakaran N, Wongpakaran T: A revised Thai Multi-Dimensional Scale of Perceived Social Support. Span J Psychol 2012, 15(3):1503-1509.

14. Wongpiromsarn Y, Lortrakul P, Wanitrommanee K, Inseeyoung V, Sukmak K, Usaha S: The Development of the emotional intelligence screening test for the Thai population aged 12 to 60 years. J Psychaitr Assoc Thai 2002, 47(4):267-280. 
15. Siriwan U, Thitikalaya N, Soonthonsmai V, Ramabut C, Plomelersee S, Ha M: A confirmatory factor analysis of the emotional quotient management model. International Journal of Arts \& Sciences 2015, 8(4):303.

16. Sitasuwan T, Bussaratid S, Ruttanaumpawan P, Chotinaiwattarakul W: Reliability and validity of the Thai version of the Pittsburgh Sleep Quality Index. J Med Assoc Thai 2014, 97(Suppl 3):S57-S67.

17. Lotrakul M, Sumrithe S, Saipanish R: Reliability and validity of the Thai version of the PHQ-9. BMC Psychiatry 2008, 8(1):46.

18. Kennedy SH, Lam RW, Mclntyre RS, Tourjman SV, Bhat V, Blier P, Hasnain M, Jollant F, Levitt AJ, MacQueen GM: Canadian Network for Mood and Anxiety Treatments (CANMAT) 2016 clinical guidelines for the management of adults with major depressive disorder: section 3. Pharmacological treatments. The Canadian Journal of Psychiatry 2016, 61(9):540-560.

19. Carod-Artal FJ, Vázquez-Cabrera C: Burnout syndrome in an international setting. In: Burnout for experts. edn.: Springer; 2013: 15-35.

20. Gómez-Gascón T, Martín-Fernández J, Gálvez-Herrer M, Tapias-Merino E, Beamud-Lagos M, MingoteAdán JC: Effectiveness of an intervention for prevention and treatment of burnout in primary health care professionals. BMC Family Practice 2013, 14(1):1-7.

21. Ramirez AJ, Graham J, Richards M, Gregory W, Cull A: Mental health of hospital consultants: the effects of stress and satisfaction at work. The Lancet 1996, 347(9003):724-728.

22. Patel RS, Bachu R, Adikey A, Malik M, Shah M: Factors related to physician burnout and its consequences: a review. Behavioral sciences 2018, 8(11):98.

23. Williams D, Tricomi G, Gupta J, Janise A: Efficacy of burnout interventions in the medical education pipeline. Academic Psychiatry 2015, 39(1):47-54.

24. Beutel ME, Klein EM, Brähler E, Reiner I, Jünger C, Michal M, Wiltink J, Wild PS, Münzel T, Lackner KJ: Loneliness in the general population: prevalence, determinants and relations to mental health. $B M C$ psychiatry 2017, 17(1):97.

25. Boomsma DI, Willemsen G, Dolan CV, Hawkley LC, Cacioppo JT: Genetic and environmental contributions to loneliness in adults: The Netherlands Twin Register Study. Behavior genetics 2005, 35(6):745-752.

26. Heinrich LM, Gullone E: The clinical significance of loneliness: A literature review. Clinical psychology review 2006, 26(6):695-718.

27. Masi CM, Chen H-Y, Hawkley LC, Cacioppo JT: A meta-analysis of interventions to reduce loneliness. Personality and Social Psychology Review 2011, 15(3):219-266.

28. Martin B, Varney W: Nonviolence and communication. Journal of Peace Research 2003, 40(2):213232.

29. Grahek I, Shenhav A, Musslick S, Krebs RM, Koster EH: Motivation and cognitive control in depression. Neuroscience \& Biobehavioral Reviews 2019, 102:371-381. 
30. Naseem K: Job stress, happiness and life satisfaction: The moderating role of emotional intelligence empirical study in telecommunication sector Pakistan. Journal of Social Sciences and Humanity Studies 2018, 4(1):7-14.

31. Rohrer JM, Richter D, Brümmer M, Wagner GG, Schmukle SC: Successfully striving for happiness: Socially engaged pursuits predict increases in life satisfaction. Psychological Science 2018, 29(8):1291-1298.

32. Cohn MA, Fredrickson BL, Brown SL, Mikels JA, Conway AM: Happiness unpacked: positive emotions increase life satisfaction by building resilience. Emotion 2009, 9(3):361.

33. Lee $Y-C$, Lin $Y-C$, Huang C-L, Fredrickson BL: The construct and measurement of peace of mind. Journal of Happiness studies 2013, 14(2):571-590.

34. Savel RH, Munro CL: Quiet the mind: Mindfulness, meditation, and the search for inner peace. In.: AACN; 2017.

\section{Figures}

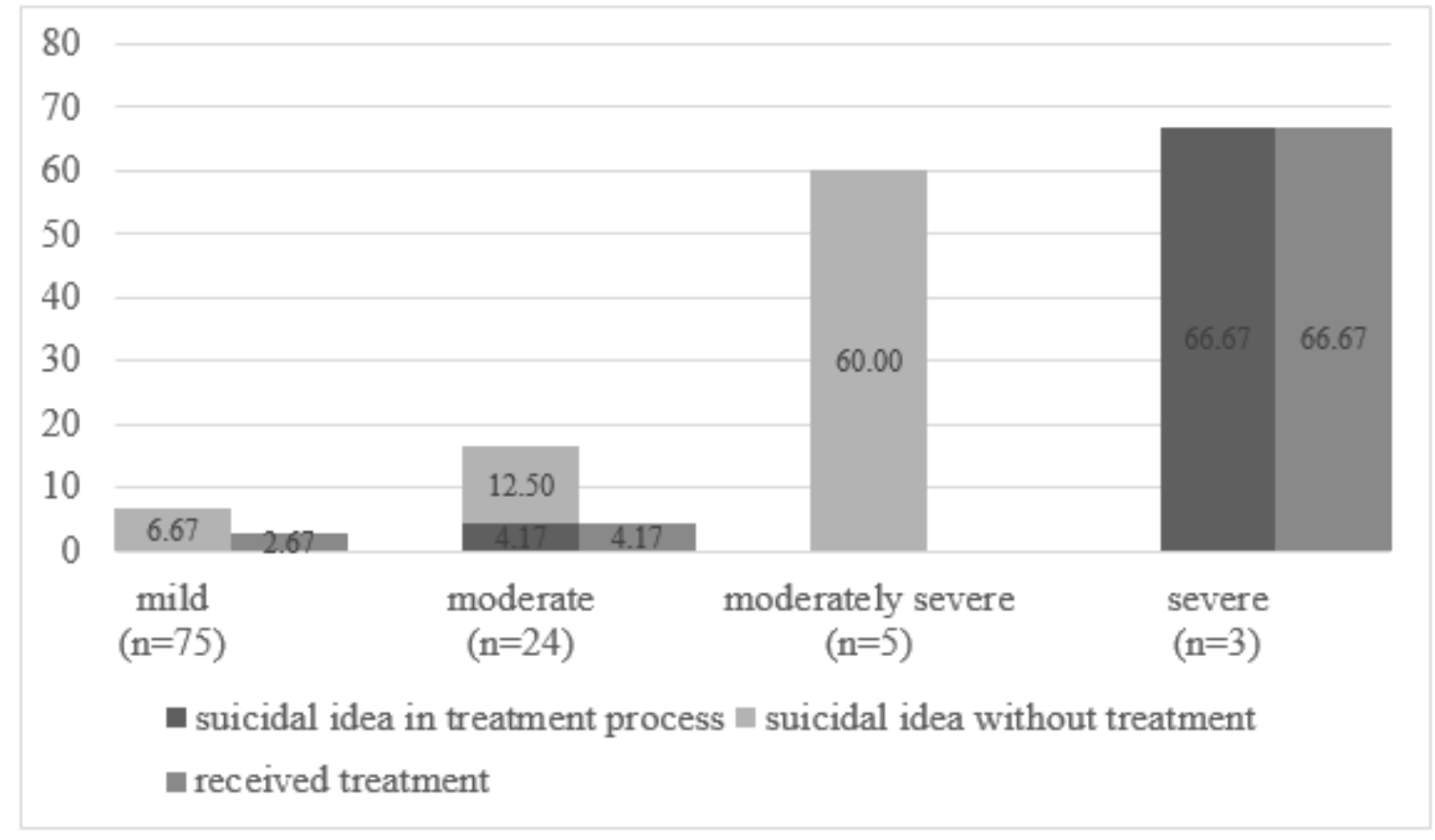

Figure 1

Percentage of having suicidal idea and receiving treatment regard severity of depression 